\title{
A rare case of bilateral spontaneous tubal ectopic pregnancy
}

\section{Sayali Shripad Jahagirdar*, Pushpa Shankarrao Junghare}

Department of Obstetrics \& Gynecology, PDMMC, Amravati, Maharashtra, India

Received: 28 August 2014

Accepted: 19 September 2014

*Correspondence:

Dr. Sayali Shripad Jahagirdar,

E-mail: rupasi2001@yahoo.co.in

Copyright: (C) the author(s), publisher and licensee Medip Academy. This is an open-access article distributed under the terms of the Creative Commons Attribution Non-Commercial License, which permits unrestricted non-commercial use, distribution, and reproduction in any medium, provided the original work is properly cited.

\begin{abstract}
A 30 year old woman with 40 days amenorrhoea presented with complains of pain in lower abdomen and blackish discharge per vaginum for 2 days. After investigations and ultrasound, she was diagnosed to have ruptured left tubal ectopic pregnancy. On exploratory laparotomy, patient had ruptured left tubal ectopic pregnancy and unruptured ampullary right tubal ectopic. After appropriate counseling salpingectomy was done on left side and removal of intact ectopic sac by salpingotomy followed by recanalization was done for right tube. Histopathology proved presence of bilateral ectopic pregnancy. Hysterosalpingography done 3 months later confirmed patency of right fallopian tube thus giving hope of natural conception. Spontaneous bilateral ectopic pregnancy is an extremely rare condition which most of the times is not diagnosed preoperatively. Conservative management is possible in a few cases after proper counseling.
\end{abstract}

Keywords: Bilateral, Spontaneous, Tubal ectopic

\section{INTRODUCTION}

Bilateral tubal ectopic pregnancy is a rare condition but has great potential for causing maternal mortality and morbidity. Its true incidence is not known, but it is being reported with increasing frequency in recent times because of increase in use of artificial reproductive techniques. Diagnosis depends upon high index of suspicion, good ultrasound imaging and judicious look at the contralateral tube during surgery on an affected tube. ${ }^{1}$ Bilateral tubal ectopic pregnancy may be spontaneous as in our case.

\section{CASE REPORT}

A 30 year old female patient presented to our hospital in casualty with complaints of pain in lower abdomen and giddiness since morning. She had delayed menses for 10 days and brownish discharge per vaginum for 2 days. Her previous menstrual cycles were regular. She had a 4 year old daughter born by caesarean section done for meconium stained liquor. There was no history of $\mathrm{Cu}-\mathrm{T}$ insertion, use of ovulation induction drugs or pelvic inflammatory disease.

On general examination patient was conscious, cooperative. She was very pale although her vital parameters were stable. On abdominal examination there was minimal tenderness in lower abdomen but no guarding or rigidity. On bimanual examination uterus was normal in size with fullness in left fornix and cervical movements were tender. Urine pregnancy test was strongly positive. A clinical diagnosis of left sided ectopic pregnancy was made. Blood investigations were done which showed $\mathrm{Hb} 5.8 \mathrm{gm} \%$, rest were within normal limits. Ultrasound pelvis showed normal sized uterus with $9 \mathrm{~mm}$ endometrial thickness. A well-defined iso-hyperechoic lesion measuring $47 \times 42 \times 34 \mathrm{~mm}$ in left adnexal region separate from left ovary. The lesion showed mild to moderate vascularity with low resistance diastolic flow. Mild free fluid in abdomen, pelvis and pouch of Douglas with echoes. Both ovaries normal. Ultrasound report was suggestive of ruptured left tubal ectopic pregnancy. 
Patient was posted for emergency laparotomy after written informed valid consent. Exploratory laparotomy was done under GA. Intraoperatively there was massive hemoperitoneum of around 1.5 litres. There was left sided tubal abortion with profuse bleeding from the fimbrial end. Uterus was bulky and both ovaries were normal in size. Inspection of right fallopian tube revealed a vascular mass of size $2.5 \times 1.5 \mathrm{~cm}$ in the ampullary region which clinically appeared to be unruptured ectopic pregnancy. Patient's relatives were counseled regarding the operative finding of bilateral ectopic pregnancy, its management options and future fertility. Partial salpingectomy was done for left fallopian tube. An informed decision was made to conserve the right fallopian tube by salpingotomy followed by recanalization. The right fallopian tube was stabilized with two Babcock forceps and a small linear incision was made on the antimesenteric border of the affected segment of the tube. The entire ectopic sac was enucleated in toto very gently. Saline wash was given. The incision was closed using 3-0 vicryl with interrupted sutures in two layers over a 8 French infant feeding tube inserted through the fimbrial end of the fallopian tube. Hemostasis was achieved and tissue handling was minimal. Hemoperitoneum was drained and intraperitoneal saline wash given. Abdomen was closed in layers. The left fallopian tube and contents of the right fallopian tube were sent for histopathology. 3 units of packed red cells were given. Patient was given antibiotics, analgesics and anti-inflammatory drugs for 10 days. Inj. placentrex 2cc i.m. was given once daily for 14 days. Postoperative period was uneventful and patient was discharged on day 10 after surgery. Patient and her husband were counseled regarding possibility of recurrent ectopic pregnancy, use of barrier contraception for dual protection and prevention of pregnancy until desired. They were also explained regarding the likelihood of future reproductive impairment and the need of early follow up in case she became pregnant. Histopathology report revealed features suggestive of ectopic gestation in left fallopian tube and ectopic pregnancy in the right fallopian tube. Patient came for followup three months later and was having regular menstrual cycles. Hysterosalpingography was done after 3 months which showed patent right fallopian tube with free spill.

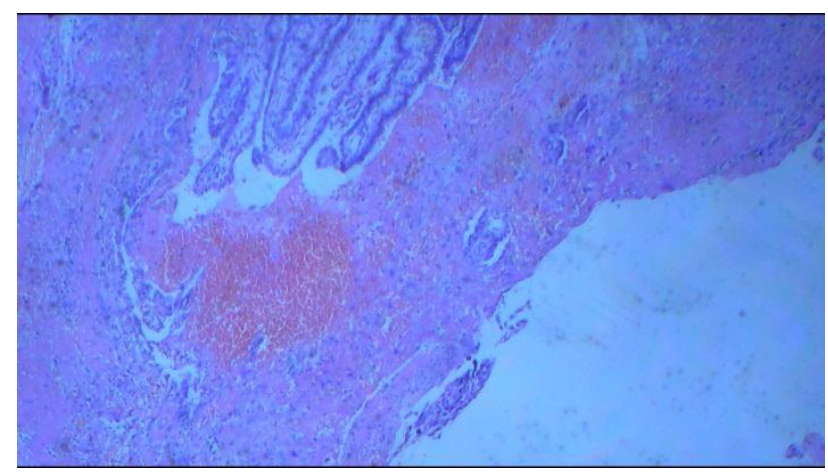

Figure 1: Chorionic villi seen invading wall of left fallopian tube.

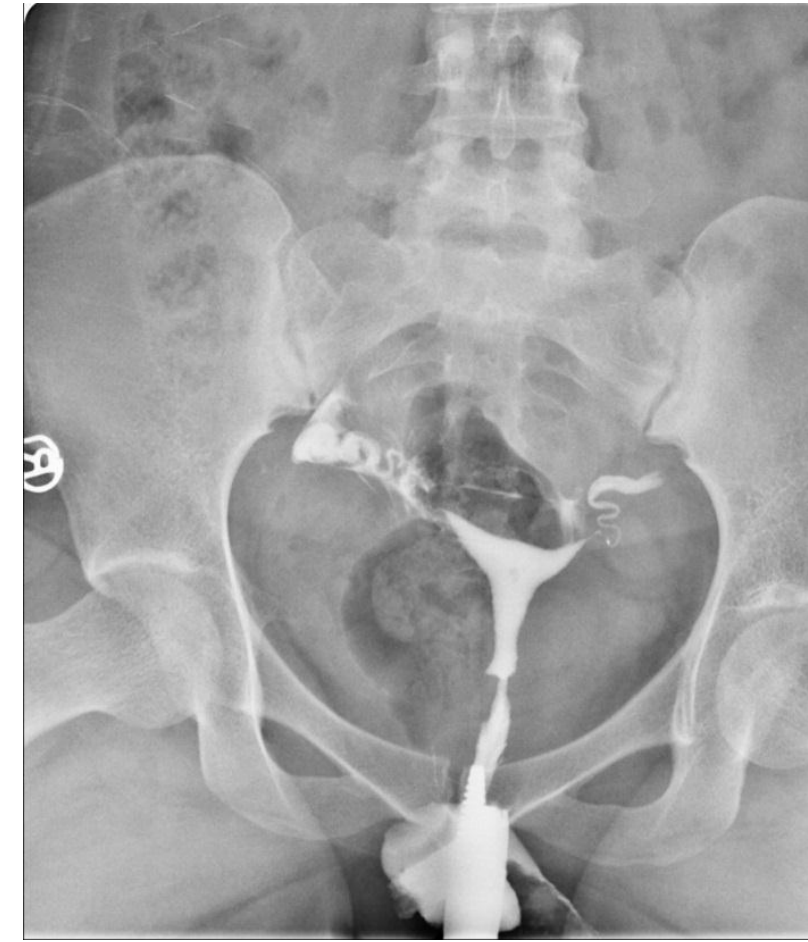

Figure 2: HSG showing patent right fallopian tube with free spill on right side and medial one third of left fallopian tube.

\section{DISCUSSION}

Bilateral tubal ectopic pregnancy is the rarest form of ectopic pregnancy. ${ }^{2}$ The incidence is reported to be five in one million deliveries. ${ }^{3}$ The postulated mechanisms of bilateral tubal ectopic pregnancy are multiple ovulation, transperitoneal migration of trophoblastic tissue from one tube to another, superfetation along with other risk factors of tubal ectopic such as pelvic inflammatory disease, use of ART, ovulation induction drugs etc. Risk factors are further enhanced by the ability of women to purchase fertility enhancing drugs over the counter without proper prescription or supervision.

The preoperative diagnosis of bilateral ectopic is seldom made. Detection with ultrasound is difficult since a high index of suspicion is required. Very few cases have been diagnosed preoperatively by ultrasound. ${ }^{4}$

During surgery for ectopic pregnancy, inspection of both tubes, ovaries and peritoneal cavity should be done. Management options should be discussed with patient and relatives in view of risk of recurrent ectopic pregnancy and impairment of future fertility. After bilateral spontaneous ectopics, there is higher risk of heterotopic pregnancies as the patient has twin proneness. $^{1}$

Treatment of bilateral ectopic pregnancy may be medical or surgical. Management depends upon condition of the patient at the time of surgery, state of the fallopian tubes, need of future fertility, availability of necessary 
instrumentation and skill of surgeon. Eze JN, Obuna JA et al. in 2012 reported 2 cases of bilateral tubal ectopic pregnancies in which conservative management (salpingotomy) of the un-ruptured fallopian tube was done with salpingectomy for the other ruptured fallopian tube after appropriate counseling. In our patient right fallopian tube was conserved so as to give her a chance for natural conception. Bilateral salpingectomy would have left the patient with no alternative other than going for IVF since she wished one more child, which is not feasible economically for most of the women in developing countries. However fertility rates reduce following previous ectopics and may worsen in presence of pre-existing infertility. ${ }^{5,6}$ Recurrent ectopic pregnancies occur in $6-16 \%$ of women with previous history of ectopics. ${ }^{7}$ It has also been observed that many women for unknown reasons fail to conceive after successful reconstructive surgery. ${ }^{6,8}$ Therefore counseling is very important. There is a need of good case selection and conservative surgery should be offered to patients only after explaining them risks of recurrent ectopic and subfertility.

In our patient emergency laparotomy was done in view of deterioration of vital parameters of patient. Future fertility rates have been found to be similar in patients who are treated surgically by laparoscopy or laparotomy. ${ }^{8}$

Ectopic pregnancies pose both health and social challenges to woman especially in developing countries where inability to child bearing is a social taboo and bilateral tubal ectopic may worsen these challenges.

\section{CONCLUSION}

Bilateral tubal ectopic pregnancy is the rarest form of ectopic pregnancy. Diagnosis requires very high index of suspicion, good ultrasound imaging, inspection of both fallopian tubes, ovaries and pelvis during surgery on ectopic. Early diagnosis prior to rupture, timely management will allow conservative management of tubes thereby preserving future fertility. Good case selection and meticulous counseling helps forestall future social and medicolegal complications.

Funding: No funding sources

Conflict of interest: None declared

Ethical approval: Not required

\section{REFERENCES}

1. Onuigbo IB, Eze JN, Okafor II. Twin pregnancies associated with two extraordinary cases of coexistence of bilateral tubal pregnancies. J Coll Med. 2007; 12:5-7.

2. Andrew J, Farell S. Spontaneous bilateral tubal pregnancy: a case report. J Obstet Gynecol Can. 2008;30(1):51-4.

3. Edelstein MC, Morgan M. Bilateral simultaneous tubal pregnancy: case report and review of literature. Obstet Gynecol Surv. 1989;44(4):250-2.

4. Sentilhes L, Bouet PE, Jalle T, Boussion F, Lefebvre-Lacoeuille C. Ultrasound diagnosis of spontaneous bilateral tubal pregnancy. Aust NZ J Obstet Gynecol. 2009;49(6):695-6.

5. Egwuata VE, Ozumba BC. Unexpectedly low ratio and falling incidence of ectopic pregnancy in Enugu, Nigeria, 1978-1981. Int J Fertil. 1987;32:113-21.

6. Eze JN. Successful intrauterine pregnancy following salpingotomy: a case report. Niger J Med. 2008; 17:360-2.

7. Jurkovic D. Ectopic pregnancy. In: Edmonds DK, eds. Dewhurst's Textbook of Obstetrics and Gynecology. 7th ed. Massachusetts: Blackwill Publishing; 2007: 106-116.

8. Schenker JG, Evvon S. New concepts in the surgical management of tubal pregnancy and the consequent postoperative results. Fertil Steril. 1983;40:709-23.

DOI: $10.5455 / 2320-1770 . i j r \operatorname{cog} 20141249$

Cite this article as: Jahagirdar SS, Junghare PS. A rare case of bilateral spontaneous tubal ectopic pregnancy. Int J Reprod Contracept Obstet Gynecol 2014;3:1116-8. 